\title{
Numerical simulation of the flow rate effect on the evolution of a negatively buoyant water jet
}

\author{
Oumaima Eleuch $^{1}$, Noureddine Latrache ${ }^{2}$, Sobhi Frikha ${ }^{1}$, Abderrahmane Khechekhouche $^{3,1}$, Zied Driss ${ }^{* 1}$ \\ ${ }^{1}$ Laboratory of Electro-Mechanic Systems (LASEM), National School of Engineers of Sfax (ENIS), University of Sfax, TUNISIA \\ ${ }^{2}$ University of Brest, FRE CNRS 3744 IRDL, 29238 Brest, FRANCE \\ ${ }^{3}$ Technology faculty, University of El-Oued, ALGERIA \\ Email*: zied.driss@enis.tn
}

\begin{abstract}
A numerical simulation study was done on a penetrating pure water jet injected into another surrounding salt water miscible with negative buoyancy conditions. For the incompressible filtered Navier-Stokes equations and the sum of the fluid model volume, we used a transient Computational Fluid Dynamics (CFD) solver (VOF model). A finite volume discretization method using Open Source code given in Open Foam 2.3.0. was used to solve these equations. The flow has a significant impact in the laminar system on the evolution of the jet in terms of subsequent permanent phase as well as transient regime.
\end{abstract}

Keywords: Pure water jet, saltwater, transient penetration, stationary profile.

Received: 21/11/2020 - Accepted: 25/12/2020

\section{Introduction}

The mixing of fluids at a difference in temperature, concentration or density has been the subject of several scientific studies in the world. When a fluid is pumped into another fluid of different density, fountains or negatively buoyant plumes arise where the buoyancy force opposes the momentum flux. Prior to collapsing back around itself, the injected fluid penetrates a distance into the environment. In a number of configurations, including round fountains, planar fountains, fountains affecting a solid surface and fountains penetrating an interface, there have been various studies examining fountain behavior. Depending on the ratio of buoyancy and momentum flux, and also as laminar or turbulent, fountain flow can be defined as weak or forced. Using numerical simulation over the parametric range $0.25<\mathrm{Fr}<10,50<\operatorname{Re}<150, \operatorname{Pr}=7,300$ and 700 [1], the findings show that the behavior of plane laminar fountains with parabolic velocity inlet profile. The flow behavior is most strongly influenced by the number of Froude and, to a lesser extent, by the number of Reynolds, especially for poor fountains at low numbers of Reynolds. In order to examine their results, a group of researchers examined the upward discharge of a floating plume in a two-layer stratified ambient medium and used the phenomenon of the stratification which is based on the difference in the density parameter in the flow [2]. The turbulent fountains were the subject of most early studies [3-5]. In comparison, only a few studies have been devoted to the case of laminar jets. In these cases, the weak laminar plane fountains exhibit both a uniform and parabolic profile of the discharge velocity at the source. In addition, the original, temporary and final characteristics of the fountain heights and the times for the front of the fountain to hit these heights were calculated and scaled [6].

The effect of flow rate on the penetration of a laminar pure water jet within miscible saltwater is investigated numerically in this paper. The increase in the flow rate allows the penetration depth to increase and the steadystate phase to be steadily reached.

\section{Numerical method}

The 3D numerical method was adopted to simulate the flow of the buoyant pure water jet in miscible saltwater. 
The laminar flow is governed by the equations of NavierStokes and the volume of the fluid model with the Boussinesq approximation, which were solved by the finite volume method treated by Open Foam [7]. The further dependence test of the mesh is performed to a grid system of $77 \times 150 \times 77$. Figure 1 presents the computational domain and boundary conditions. The inlet boundary of the jet is defined as velocity-inlet. A value of $\mathrm{p}=101325 \mathrm{~Pa}$ is known for the outlet pressure, which means that the fluid will exit the model to an environment of static atmospheric pressure at the opening of the tank, where the nozzle is.

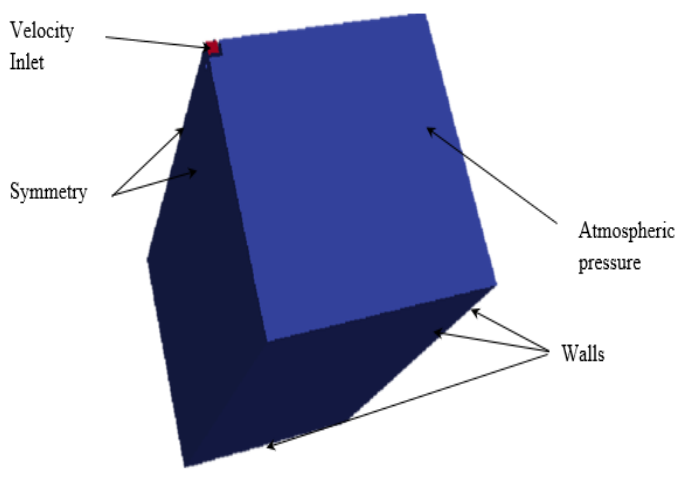

Figure 1. Boundary conditions

\section{Results and Discussion}

\section{III.1. Volume fraction}

The jet evolution penetrates in the salt water through the nozzle with a diameter $\mathrm{D}=1.37 \mathrm{~mm}$ and for different values of the flow rate equal to $\mathrm{Q}=0.047 \mathrm{~cm}^{3} \cdot \mathrm{s}^{-1}, \mathrm{Q}=$ $0.065 \mathrm{~cm}^{3} \cdot \mathrm{s}^{-1}, \mathrm{Q}=0.086 \mathrm{~cm}^{3} \cdot \mathrm{s}^{-1}$ and $\mathrm{Q}=0.132 \mathrm{~cm}^{3} \cdot \mathrm{s}^{-1}$. The results obtained are shown in the figures for different instances equal to $\mathrm{t}=0.08 \mathrm{~s}$ in Figure $2, \mathrm{t}=0.25 \mathrm{~s}$ in Figure 3, $\mathrm{t}=0.5 \mathrm{~s}$ in Figure $4, \mathrm{t}=1 \mathrm{~s}$ in Figure 5 and $\mathrm{t}=$ $1.5 \mathrm{~s}$ in Figure 6.

Based on these results, it has been observed an increase in the depth and the width of the jet in each instance when the flow rate increases. This fact is due to the increase of the initial velocity of the flow with a constant section of the nozzle that allows the increase of the Reynolds number corresponding to a laminar regime. In these conditions, it has been observed that there is more mixing layer in the boundary between the jet of lighter water and the denser water when the flow rate rises. Indeed, the head of the jet contains more pure water $(\alpha=1)$ for the small values of the flow rate $\mathrm{Q}$.

At $\mathrm{t}=0.08 \mathrm{~s}$
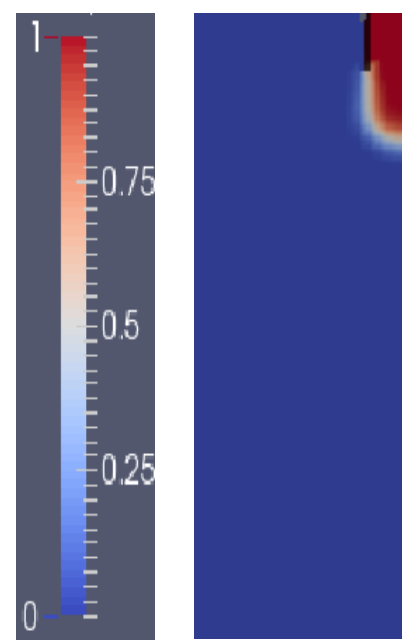

(a)

$\mathrm{Q}=0.047 \mathrm{~cm}^{3} \cdot \mathrm{s}^{-1}$
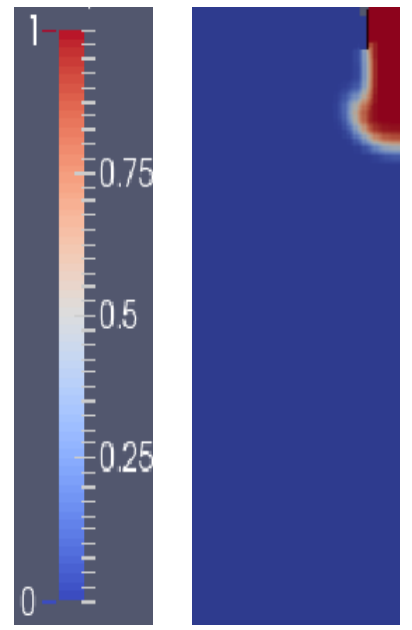

(c)

$\mathrm{Q}=0.086 \mathrm{~cm}^{3} \cdot \mathrm{s}^{-1}$

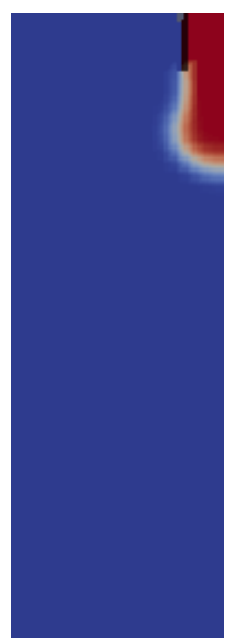

(b)

$\mathrm{Q}=0.065 \mathrm{~cm}^{3} \cdot \mathrm{s}^{-1}$

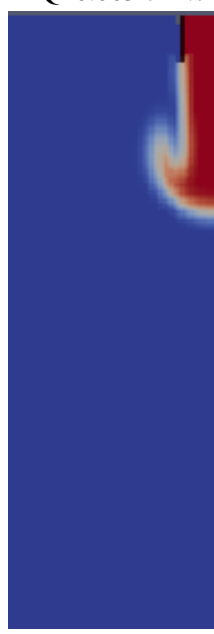

(d)

$\mathrm{Q}=0.132 \mathrm{~cm}^{3} \cdot \mathrm{s}^{-1}$
Figure 2. Distribution of the volume fraction of the jet in the plane $\mathrm{z}=0$ $\mathrm{mm}$ at $\mathrm{t}=0.08 \mathrm{~s}$

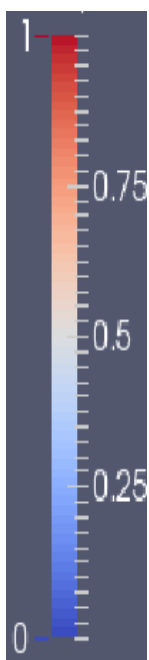

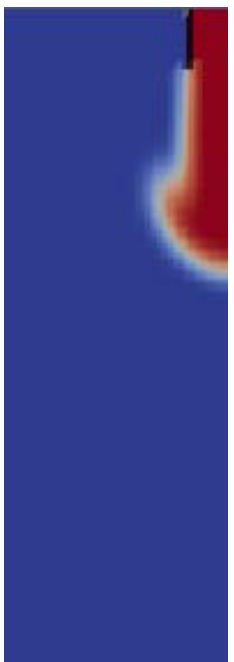

(a)

$\mathrm{Q}=0.047 \mathrm{~cm}^{3} \cdot \mathrm{s}^{-1}$

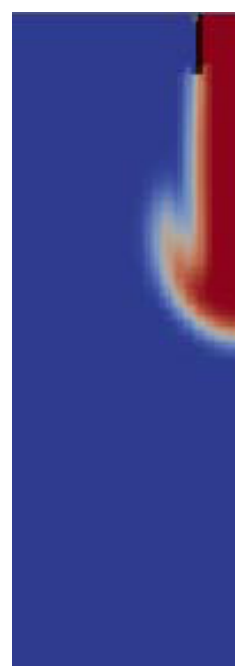

(b)

$\mathrm{Q}=0.065 \mathrm{~cm}^{3} \cdot \mathrm{s}^{-1}$ 

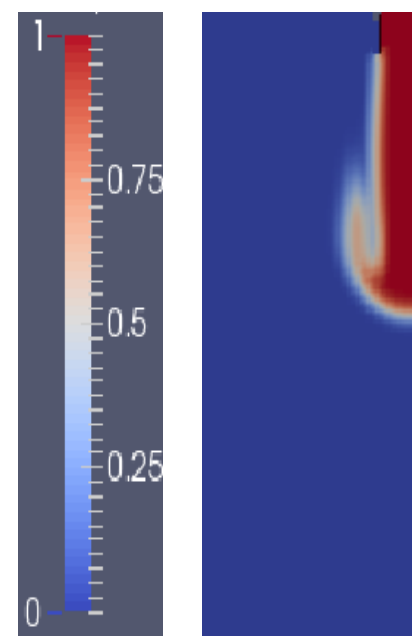

(c)

$\mathrm{Q}=0.086 \mathrm{~cm}^{3} \cdot \mathrm{s}^{-1}$

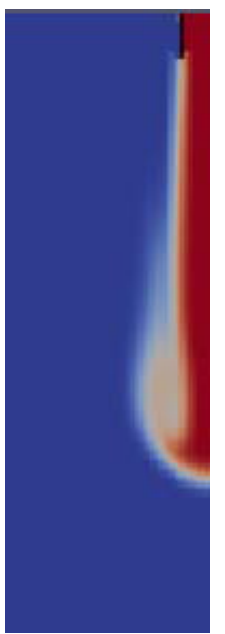

(d)

$\mathrm{Q}=0.132 \mathrm{~cm}^{3} \cdot \mathrm{s}^{-1}$

Figure 3. Distribution of the volume fraction of the jet in the plane $\mathrm{z}=0$ $\mathrm{mm}$ at $\mathrm{t}=0.25 \mathrm{~s}$
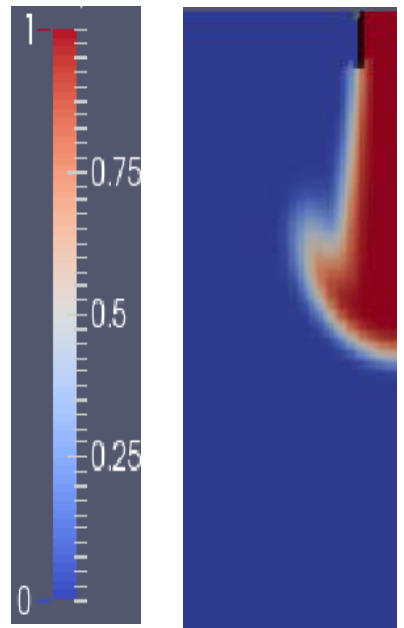

(a) $\mathrm{Q}=0.047 \mathrm{~cm}^{3} \cdot \mathrm{s}^{-1}$
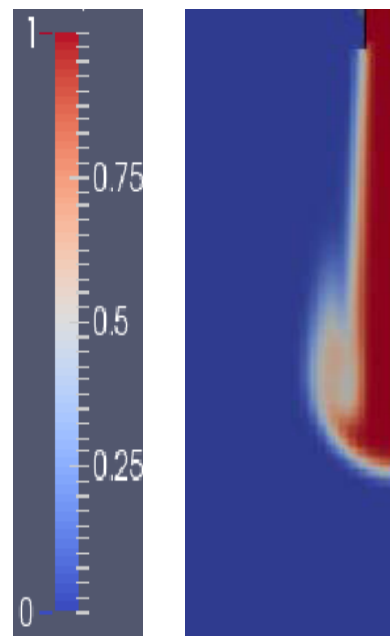

(c)

$\mathrm{Q}=0.086 \mathrm{~cm}^{3} \cdot \mathrm{s}^{-1}$

$\mathrm{Q}=0.132 \mathrm{~cm}^{3} \cdot \mathrm{s}^{-1}$

Figure 4. Distribution of the volume fraction of the jet in the plane $\mathrm{z}=0$ $\mathrm{mm}$ at $\mathrm{t}=0.5 \mathrm{~s}$

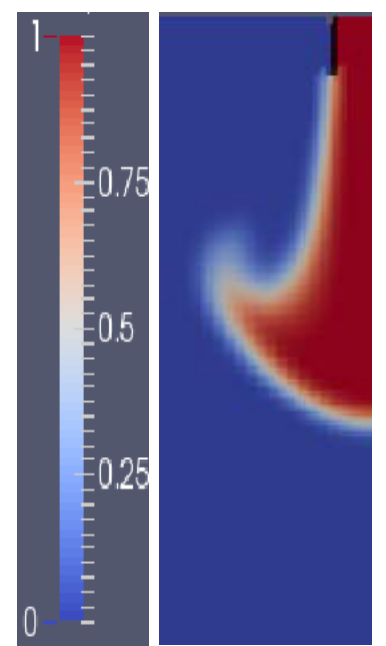

(a)

$\mathrm{Q}=0.047 \mathrm{~cm}^{3} \cdot \mathrm{s}^{-1}$
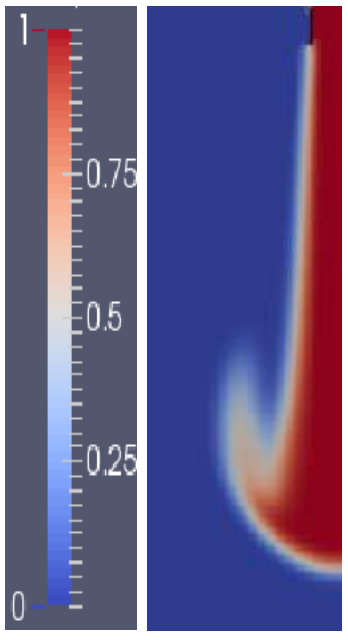

(c)

$\mathrm{Q}=0.086 \mathrm{~cm}^{3} \cdot \mathrm{s}^{-1}$

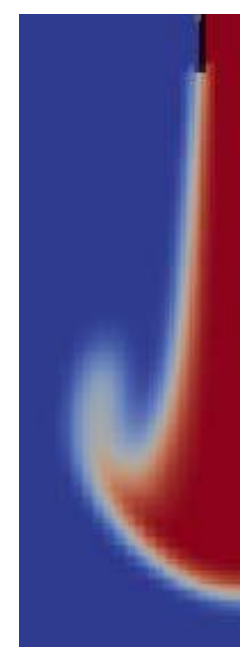

(b)

$\mathrm{Q}=0.065 \mathrm{~cm}^{3} \cdot \mathrm{s}^{-1}$

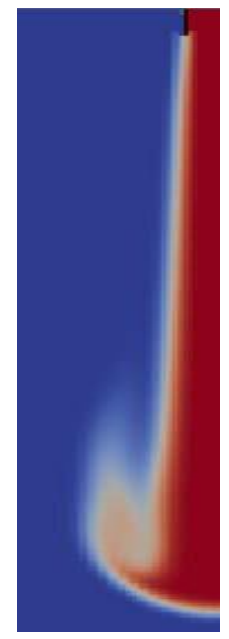

(d)
Figure 5. Distribution of the volume fraction of the jet in the plane $\mathrm{z}=0$ $\mathrm{mm}$ at $\mathrm{t}=1 \mathrm{~s}$

\section{III.2. Transient penetration}

The beginning of penetration of the liquid jet is made by the initial velocity. This velocity decreases up to zero because of the inverse buoyancy force and the viscous drag in the whole tank despite that the jet continues to penetrate in the outer liquid by gravity effect. In this transient regime, we have performed for a few values of the flow rate $\mathrm{Q}$ the temporal evolution of the depth as shown in Figure 6. According to these data, it has been reported that the depth of the penetration increases with the flow rate Q. Furthermore, the jet takes more time in the transient penetration for the high flow rate. However, when the flow rate decreases, the maximum depth and the steady-state system are easily reached by the jet. In Table 1, the maximal penetration depth of the jet and the transient time needed to achieve this maximal depth are summarized for four flow rates in the same conditions. 


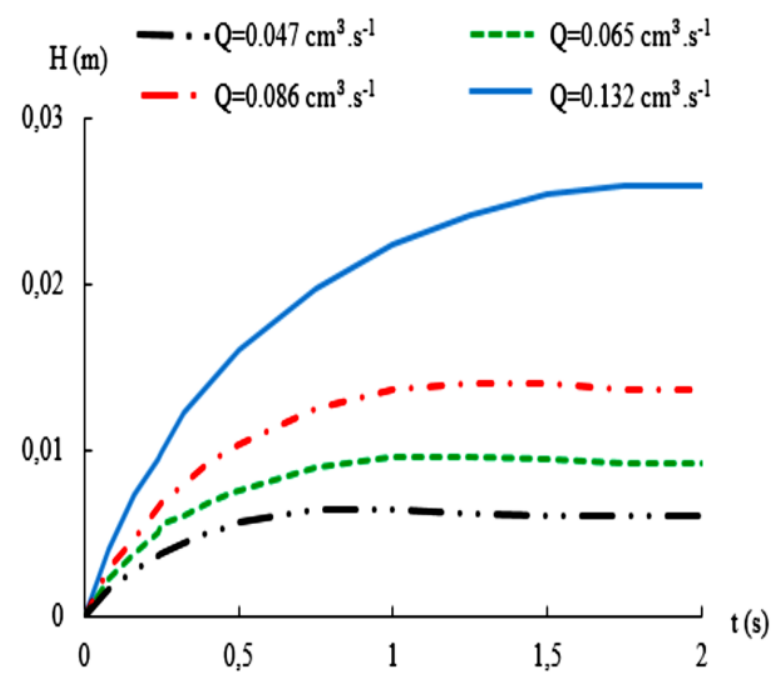

Figure 6. Penetration of the jet head

Table 1. Variation of the maximal penetration depth for four different flow rates

\begin{tabular}{|c|c|c|}
\hline $\begin{array}{c}\text { Flow rate } \\
\mathrm{Q}\left(\mathrm{cm}^{3} \cdot \mathrm{s}^{-1}\right)\end{array}$ & $\begin{array}{c}\text { Time } \\
\mathrm{t}(\mathrm{s})\end{array}$ & $\begin{array}{c}\text { Maximal penetration depth } \\
\mathrm{H}(\mathrm{m})\end{array}$ \\
\hline 0.047 & 0.75 & 0.0064 \\
\hline 0.065 & 1 & 0.0096 \\
\hline 0.086 & 1.5 & 0.014 \\
\hline 0.132 & 2 & 0.02595 \\
\hline
\end{tabular}

\section{III.3. Stationary profile of the jet}

The variance of the penetration depth $\mathrm{H}$ of the jet is presented in Figure 7 as a function of it's a dimensionless width at four different injection flow rates. These results confirm that the profile of the jet in depth and width at the same time just after the steady-state is reached under the same condition. For each value of $\mathrm{Q}$, the curve has a horizontal asymptote in $\mathrm{H}=\mathrm{H}_{\mathrm{s}}$. Indeed, it has been observed that once the jet penetrates the tank, the depth increases with the width in the transient phase with the presence of miscibility between the outer and the inner liquids. When the jet reaches the steady-state regime and the depth rest constant with $\mathrm{H}=\mathrm{H}_{\mathrm{s}}$ in few seconds before rising back, the head of the jet continues to expel radially.

To compare between the considered flow rates, it has been observed that for the big value of flow rate $\mathrm{Q}=0.132$ $\mathrm{cm}^{3} \cdot \mathrm{s}^{-1}$, the jet is wider and spreads easily despite it needs more time to reaches the steady-state regime. Thus, the decreasing of the flow rate allows decreasing of the width of the jet with low penetration depth and fast steady-state phase.

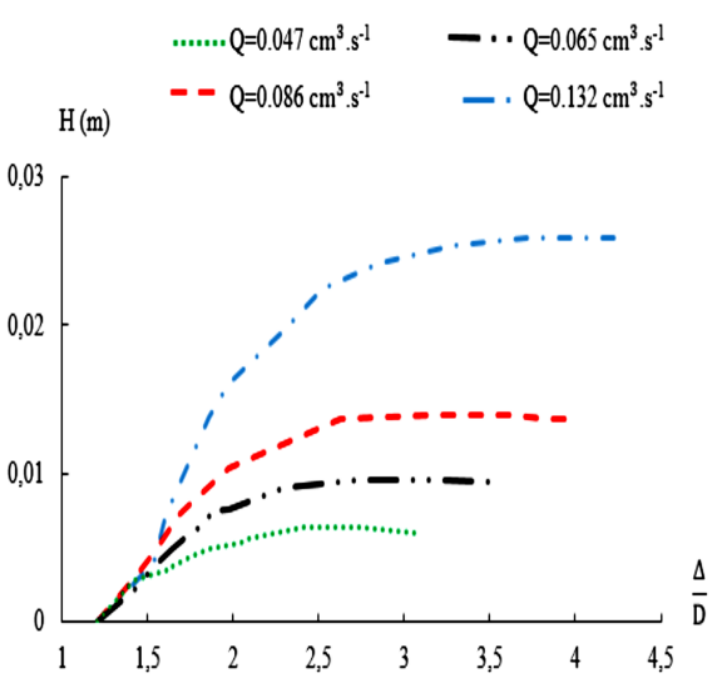

Figure 7. Profile of the jet for different flow rates

\section{Conclusion}

In this paper, negatively buoyant jet flow, induced by vertical injection of pure water downward into saltwater, has been affected by the flow rate of the jet. The numerical results show that the penetration depth of the jet inside the denser water increases with the increase of the flow rate. Whereas, the jet reaches slowly the maximal depth and the stationary regime.

\section{Nomenclature}

$\begin{array}{ll}\mathrm{D} & : \text { Diameter }(\mathrm{mm}) \\ \mathrm{Fr} & : \text { Froude number } \\ \mathrm{H} & : \text { Penetration depth }(\mathrm{m}) \\ \mathrm{P} & : \text { Pressure }(\mathrm{Pa}) \\ \mathrm{Pr} & : \text { Prandtl number } \\ \mathrm{Q} & : \text { Flow rate }\left(\mathrm{cm}^{3} \cdot \mathrm{s}^{-1}\right) \\ \mathrm{Re} & : \text { Reynolds number } \\ \mathrm{t} & : \text { Time }(\mathrm{s}) \\ \mathrm{V} & : \text { Velocity }(\mathrm{m} / \mathrm{s}) \\ \alpha & : \text { Jet contains, } \alpha=1 \text { for pure water }\end{array}$

\section{References}

[1] N. Srinarayana, S.W. Armfield, L. Wenxian, "Behavior of laminar plane fountains with a parabolic inlet velocity profile in a homogeneous fluid", International Journal of Thermal Sciences, Vol 67, 2013, pp. 87-95.

[2] G. Noutsopoulos, K. Nanou, "The round jet in a two-layer stratified ambient", Proc. Intl Symp. on Buoyant Flows: Athens-Greece 1-5, 1986, pp. 165-183.

[3] T. Mizushina, F. Ogino, H. Takeuchi, H. Ikawa, "An experimental study of vertical turbulent jet with negative buoyancy", Warme and Stoffubertragung (Thermo and 
Fluid Dynamics), Vol 16, 1982, pp. 15-21.

[4] I. H. Campbell, J. S. Turner, "Fountains in magma chambers", Journal of Petrology, Vol 30, 1989, pp. 885923.

[5] W. D. Bains, J. S. Turner, I. H. Campbell, "Turbulent fountains in an open chamber", J. Fluid Mech 212, 1990, pp. 557-592.

[6] W. Lin, S. W. Armfield, "Direct simulation of weak laminar plane fountains in a homogeneous fluid", International Journal of Heat and Mass Transfer, Vol 43, 2000, pp. 3013-3026.

[7] Z. Driss, O. Mlayah, S. Driss, M. Maaloul, M. S. Abid, "Study of the incidence angle effect on the aerodynamic structure characteristics of an incurved Savonius wind rotor placed in a wind tunnel", Energy, Vol 113, 2016, pp. 894-908. 